\title{
Structure evolution of thiophene-containing conjugated polymer photocatalysts for high-efficiency photocatalytic hydrogen production
}

\author{
Sihui Xiang, Changzhi Han, Chang Shu, Chong Zhang* and Jia-Xing Jiang*
}

\begin{abstract}
Conjugated polymer photocatalysts have received extensive attention in the field of photocatalytic hydrogen evolution owing to their tunable molecular structures and electronic properties. Herein, we developed three donoracceptor (D-A) type thiophene-containing narrow-band-gap conjugated polymers with pyrene as a donor and different fused-thiophene derivatives as acceptors via direct $\mathrm{C}-\mathrm{H}$ arylation coupling polymerization. It was found that the band gap of the polymers can be tuned by adjusting the number of the fused-thiophene rings. The visible light absorption range can be extended by increasing the number of the thiophene rings, the planar molecular structure for both donor and acceptor units facilitates the charge transmission along the polymer skeleton, and the $\mathrm{D}$-A type polymer structure promotes the dissociation of photo-induced electrons and holes. As a result, a high photocatalytic hydrogen evolution rate of $33.07 \mathrm{mmol} \mathrm{h}^{-1} \mathrm{~g}^{-1}$ was obtained by PyTP-2 with an optimized molecular structure under visible light irradiation $(\lambda>$ $420 \mathrm{~nm}$ ) without the aid of Pt co-catalyst. In addition, PyTP-2 also shows a photocatalytic activity for oxygen evolution with an average oxygen evolution rate of $58.37 \mu \mathrm{mol} \mathrm{h}^{-1} \mathrm{~g}^{-1}$.
\end{abstract}

Keywords: conjugated polymer, photocatalysis, fused-thiophene ring, hydrogen evolution, oxygen evolution

\section{INTRODUCTION}

Given the ever-increasing energy consumption and the serious environmental pollution, hydrogen energy, as a kind of green and renewable energy system, will be an ideal alternative to the traditional fossil energy [1-3]. Sunlight-driven water splitting technology using photocatalytic materials as media is a sustainable approach to produce hydrogen, which provides a solution to the energy shortage and environmental pollution $[4,5]$. Due to the pivotal role of photocatalysts in the photocatalytic hydrogen evolution reaction, plenty of studies have been done to find efficient and inexpensive catalysts [6-8]. Compared with inorganic semiconductor materials, organic semiconductor materials recently attract more interest because of their flexible structural design, diverse synthetic strategies and tunable electronic properties [9-14]. To date, the developed organic polymer photocatalysts mainly include graphitic carbon nitrides [15-17], linear conjugated polymers [18-22], conjugated microporous polymers (CMPs) [23-27], crystalline covalent organic frameworks (COFs) [28-31] and covalent triazine-based frameworks (CTFs) [32-35].

In the past years, significant advances have been achieved for the preparation of organic polymer photocatalysts, particularly for the photocatalytic activity [36-38]. Generally, an efficient polymer photocatalyst should have a broad spectral absorption range, fast transmission ability of charge carriers, high separation capability of light-induced electrons and holes, and high hydrophilicity, which could be controlled by the structural design and component tuning on the macromolecular chains. For example, it has been proved that constructing a donoracceptor (D-A) molecular structure could be an efficient strategy to promote the photocatalytic activity due to the enhanced dissociation efficiency of photo-induced electrons and holes in the D-A polymer photocatalyst [39-42]. In addition, dibenzothiophene-S,S-dioxide (BTDO), possessing strong electronwithdrawing ability, planar structure and high hydrophilicity, has been widely studied as an electron acceptor for improving photocatalytic performance of polymeric photocatalysts. For instance, a BTDO-containing conjugated polymer of BTT-CPP exhibited a high hydrogen evolution rate (HER) of $37.88 \mathrm{mmol} \mathrm{h}^{-1} \mathrm{~g}^{-1}$ under broadband irradiation and an HER of $12.63 \mathrm{mmol} \mathrm{h}^{-1} \mathrm{~g}^{-1}$ under visible light [40]. The triazine-based polymer of triazine-Ph-CPP showed high HER values of 16.28 and $3.50 \mathrm{mmol} \mathrm{h}^{-1} \mathrm{~g}^{-1}$ upon broadband light and visible light irradiation, respectively [43]. A fluorine-functionalized CMP photocatalyst of PyDF exhibited the HER values as high as 18.93 and $13.47 \mathrm{mmol} \mathrm{h}^{-1} \mathrm{~g}^{-1}$ under $\mathrm{UV}$-Vis light and visible light, respectively [39]. Nevertheless, the photocatalytic performance of polymeric photocatalysts under visible light is still unsatisfactory due to the broad band gap and weak light absorption to visible light for most reported polymer photocatalysts. Although conjugated polymers derived from thiophene-based building blocks presented narrow band gaps and broad light absorption, the photocatalytic activity was yet pretty low $[44,45]$. For example, the all-thiophene based polymer P17 showed a narrow band gap of $1.89 \mathrm{eV}$ but a low HER of $10 \mu \mathrm{mol} \mathrm{h}^{-1} \mathrm{~g}^{-1}$ under broadband light irradiation [45]. The low HER could be ascribed to the fast combination of photo-induced electrons and holes due to the absence of D-A structure in P17. Similar result was also observed for the polythiophene nanofibers produced from bithiophene, though an HER value of $2.19 \mathrm{mmol} \mathrm{h}^{-1} \mathrm{~g}^{-1}$ was obtained [44]. Recently, we reported a series of narrowband-gap polymer photocatalysts with the D-A type structure and high photocatalytic activity by integrating pyrene with strong electron-donating ability and dithieno[3,2-b:2',3'-d] thio-

Key Laboratory for Macromolecular Science of Shaanxi Province, Shaanxi Engineering Laboratory for Advanced Energy Technology, School of Materials Science and Engineering, Shaanxi Normal University, Xi'an 710062, China

* Corresponding authors (emails: chongzhangabc@snnu.edu.cn (Zhang C); jiaxing@snnu.edu.cn (Jiang JX)) 
phene-S,S-dioxide with strong electron-withdrawing ability into a polymer skeleton, and a high HER of $16.32 \mathrm{mmol} \mathrm{h}^{-1} \mathrm{~g}^{-1}$ was obtained under visible light irradiation [8].

Herein, we developed three thiophene-containing CMP photocatalysts with narrow band gaps and studied the influence of the acceptor structure on the photocatalytic activity. We expect that the planar molecular structure of the acceptor units (e.g., thieno[3,2-b]thiophene and dithieno[3,2-b:2',3'-d]thiophene) could extend the spectral absorption range and facilitate the transmission of charge carriers of the resulting polymer photocatalysts, thus leading to a high photocatalytic performance for hydrogen evolution under visible light. Indeed, the obtained polymers show an extended spectral absorption range with increasing number of the fused-thiophene rings. Among the three thiophene-containing CMP photocatalysts, PyTP-2 produced from thieno[3,2- $b]$ thiophene exhibits an excellent photocatalytic activity with a high HER of $33.07 \mathrm{mmol} \mathrm{h}^{-1} \mathrm{~g}^{-1}$ under visible light $(\lambda>420 \mathrm{~nm})$ without the aid of Pt co-catalyst, which could be attributed to its porous texture structure with high surface area providing plentiful available active sites, besides the broad light absorption range.

\section{EXPERIMENTAL SECTION}

\section{Chemicals}

Thiophene, thieno[3,2- $b]$ thiophene, dithieno[3,2-b:2',3'-d] thiophene, tris(dibenzylideneacetone)dipalladium $\left(\mathrm{Pd}_{2}(\mathrm{dba})_{3}\right)$, tris (2-methoxyphenyl)phosphine $\left(\mathrm{P}(\mathrm{o}-\mathrm{MeOPh})_{3}\right)$, pivalic acid (PivOH), anhydrous potassium carbonate $\left(\mathrm{K}_{2} \mathrm{CO}_{3}\right)$ and anhydrous 1,2-dimethylbenzene (ODMB) were purchased from J\&K Scientific Ltd. or Sigma-Aldrich. The monomer of 1,3,6,8-tetrabromopyrene was synthesized using the reported procedure [46]. The conjugated polymer photocatalysts were prepared by the direct $\mathrm{C}-\mathrm{H}$ arylation coupling according to the reported method [47].

\section{The synthesis of the polymer photocatalysts}

Synthesis of PyTP-1: Under $\mathrm{N}_{2}$ protection, the reaction system containing $6 \mathrm{~mL}$ of anhydrous ODMB, thiophene $(126.21 \mathrm{mg}$, $1.5 \mathrm{mmol}), \quad 1,3,6,8$-tetrabromopyrene $(258.9 \mathrm{mg}, 0.5 \mathrm{mmol})$, anhydrous $\mathrm{K}_{2} \mathrm{CO}_{3}(207.3 \mathrm{mg}, 1.5 \mathrm{mmol}), \mathrm{Pd}_{2}(\mathrm{dba})_{3}(13.7 \mathrm{mg}$, $0.015 \mathrm{mmol}), \mathrm{PivOH}(30.61 \mathrm{mg}, 0.3 \mathrm{mmol})$ and $\mathrm{P}(o-\mathrm{MeOPh})_{3}$ $\left(10.6 \mathrm{mg}, 0.03 \mathrm{mmol}\right.$ ) was stirred for $72 \mathrm{~h}$ at $100^{\circ} \mathrm{C}$. After the reaction mixture was cooled to room temperature, the mixture was filtered and the solid product was washed sequentially with methanol, deionized water, dichloromethane and tetrahydrofuran. The obtained polymer was then dried in vacuum at $100^{\circ} \mathrm{C}$ for $24 \mathrm{~h}$ to give an orange red solid powder (yield: $85.1 \%$ ). Anal. Calcd. for $\left(\mathrm{C}_{24} \mathrm{H}_{10} \mathrm{~S}_{2}\right)_{n}$ (\%): C 79.53; H 2.78; S 17.69. Found: C 72.19; H 3.79; S 17.28. The residual Pd catalyst was found to be $0.24 \mathrm{wt} \%$ from inductively coupled plasma optical emission spectroscopy (ICP-OES).

Synthesis of PyTP-2: 1,3,6,8-tetrabromopyrene (258.9 mg, $0.5 \mathrm{mmol})$, thieno[3,2-b]thiophene (140.23 mg, $1.0 \mathrm{mmol})$, anhydrous $\mathrm{K}_{2} \mathrm{CO}_{3}(207.3 \mathrm{mg}, 1.5 \mathrm{mmol}), \mathrm{PivOH}$ (30.61 mg, $0.3 \mathrm{mmol}), \mathrm{P}(o-\mathrm{MeOPh})_{3}(10.6 \mathrm{mg}, 0.03 \mathrm{mmol})$, and $\mathrm{Pd}_{2}(\mathrm{dba})_{3}$ $(13.7 \mathrm{mg}, 0.015 \mathrm{mmol})$ were used in this polymerization. After work-up, PyTP-2 was obtained as a red solid powder (yield: 95.6\%). Anal. Calcd. for $\left(\mathrm{C}_{28} \mathrm{H}_{10} \mathrm{~S}_{4}\right)_{n}$ (\%): C 70.85; H 2.12; S 27.02. Found: C 65.20; H 2.72; S 27.13. The residual Pd catalyst was found to be $0.14 \mathrm{wt} \%$ from ICP-OES.
Synthesis of PyTP-3: 1,3,6,8-tetrabromopyrene (258.9 mg, $0.5 \mathrm{mmol})$ dithieno[3,2-b:2',3'-d]thiophene (196.31 mg, $1.0 \mathrm{mmol}$ ), $\mathrm{PivOH}(30.61 \mathrm{mg}, 0.3 \mathrm{mmol})$, anhydrous $\mathrm{K}_{2} \mathrm{CO}_{3}$ (207.3 mg, $1.5 \mathrm{mmol}), \mathrm{P}(o-\mathrm{MeOPh})_{3}(10.6 \mathrm{mg}, 0.03 \mathrm{mmol})$, and $\mathrm{Pd}_{2}(\mathrm{dba})_{3}(13.7 \mathrm{mg}, 0.015 \mathrm{mmol})$ were used in this polymerization. After work-up, PyTP-3 was obtained as a deep red solid powder (yield: 70.4\%). Anal. Calcd for $\left(\mathrm{C}_{32} \mathrm{H}_{10} \mathrm{~S}_{6}\right)_{n}$ (\%): C 65.50; $\mathrm{H}$ 1.72; S 32.79. Found: C 56.87; H 2.56; S 31.03. The residual Pd catalyst was found to be $0.19 \mathrm{wt} \%$ from ICP-OES.

\section{Photocatalytic experiment}

The photocatalytic hydrogen evolution test of the as-synthesized polymers was performed on an all-glass automatic on-line trace gas analysis system (Labsolar-6A, Beijing Perfectlight Technology Co., Ltd.). In general, $10 \mathrm{mg}$ of the conjugated polymer photocatalyst was dispersed in the mixture of $90 \mathrm{~mL}$ of distilled water, $10 \mathrm{~mL}$ of dimethyl formamide (DMF) and $1.0 \mathrm{~mol} \mathrm{~L}^{-1}$ ascorbic acid (AA) by ultrasonic. After removing the dissolved air in the reaction solution and the photocatalytic system, the suspension was irradiated by a 300-W Xe lamp. A 420-nm filter was used to cut off the ultraviolet light and obtain the visible light irradiation $(\lambda>420 \mathrm{~nm})$. The temperature of photocatalytic reaction solution was kept at $6^{\circ} \mathrm{C}$ by circulating cooling water. The produced hydrogen was measured hourly with a gas chromatograph. The photocatalytic oxygen evolution experiment was also performed on a Labsolar-6A. Twenty milligram of the polymer catalyst was dispersed in $100 \mathrm{~mL}$ of aqueous solution containing $\mathrm{AgNO}_{3}\left(0.01 \mathrm{~mol} \mathrm{~L}^{-1}\right)$ as an electron scavenger, $\mathrm{Co}\left(\mathrm{NO}_{3}\right)_{2}(1 \mathrm{wt} \%)$ as a co-catalyst and $\mathrm{La}_{2} \mathrm{O}_{3}(0.2 \mathrm{~g})$ as a $\mathrm{pH}$ buffer. The reaction solution was degassed to completely remove the dissolved air, and irradiated by a $300-\mathrm{W}$ Xe lamp. The produced oxygen was measured by a gas chromatograph.

\section{RESULTS AND DISCUSSION}

All of the thiophene-containing polymer photocatalysts were prepared through a direct $\mathrm{C}-\mathrm{H}$ arylation coupling reaction. The combinations of 1,3,6,8-tetrabromopyrene with thiophene, thieno[3,2-b]thiophene and dithieno[3,2-b:2',3'-d] thiophene gave the polymers of PyTP-1, PyTP-2 and PyTP-3, respectively (Fig. 1a). Due to their rigid molecular skeletons and cross-linked polymer structures, the resulting polymers appear as orange red (for PyTP-1), red (for PyTP-2) and deep red (for PyTP-3) insoluble powder. The polymer structure was verified by solidstate ${ }^{13} \mathrm{C}$ NMR spectroscopy and Fourier-transform infrared (FT-IR) spectroscopy. As shown in Fig. 1b, all the polymers show the characteristic peak at $817 \mathrm{~cm}^{-1}$ corresponding to the stretching vibration of thiophene skeleton. Besides, the signals at 1361,1465 and $1590 \mathrm{~cm}^{-1}$ could be assigned to the stretching vibration bands of aromatic rings. The solid-state ${ }^{13} \mathrm{C} \mathrm{NMR}$ spectra and the assignment of the carbons for the three polymers are shown in Fig. 1c, and the signals corresponding to the carbon bonding with sulfur atom and pyrene unit are clearly observed at around $141 \mathrm{ppm}$ for all the polymers. The thermogravimetric analyses reveal that all of the resulting polymers exhibit a moderate thermal stability (Fig. 1d). The powder X-ray diffraction profiles demonstrate that all the polymers have an amorphous structure (Fig. S1).

The three polymers exhibit different nitrogen adsorption characters in the nitrogen adsorption and desorption measurement (Fig. 1e). PyTP-2 shows a much higher nitrogen uptake ability than PyTP-1 and PyTP-3, which leads to a higher specific 


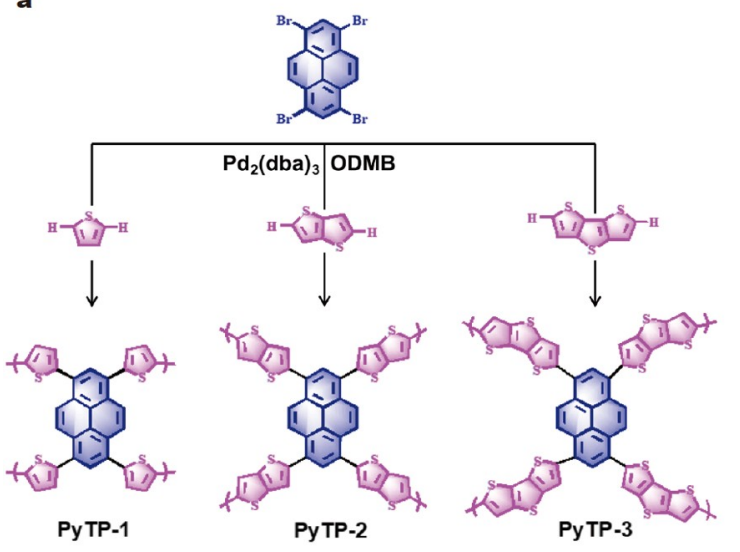

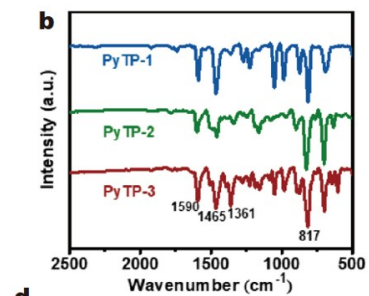
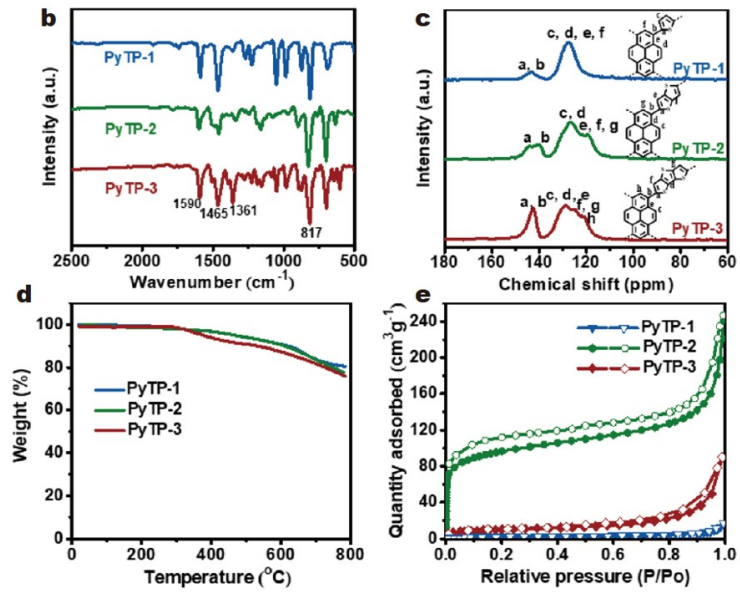

Figure 1 (a) The synthetic routes of the polymers. (b) FT-IR spectra of the polymers; (c) the solid-state ${ }^{13} \mathrm{C}$ cross-polarization magic angle spinning (CPMAS) NMR spectra and the assignment of carbons in the polymers; (d) thermogravimetric analyses of the polymers under a nitrogen atmosphere; (e) nitrogen adsorption/desorption isotherms of the polymers.

surface area of $296 \mathrm{~m}^{2} \mathrm{~g}^{-1}$ than PyTP-1 $\left(20 \mathrm{~m}^{2} \mathrm{~g}^{-1}\right)$ and PyTP-3 $\left(38 \mathrm{~m}^{2} \mathrm{~g}^{-1}\right)$, implying that the thieno[3,2-b]thiophene monomer has a higher reactivity than thiophene and dithieno[3,2-b:2',3'-d] thiophene in this direct $\mathrm{C}-\mathrm{H}$ arylation coupling reaction, which leads to a higher cross-linking degree for PyTP-2. This is also evidenced by the energy dispersive X-ray spectroscopy (EDX) spectrum, which reveals that PyTP-2 has a lower Br content from the unreacted end group of 1,3,6,8-tetrabromopyrene than PyTP-1 and PyTP-3 (Fig. 2a-c), indicative of the more complete polymerization reaction for PyTP-2. The high surface area of PyTP-2 can offer more reactive sites for the photocatalytic reaction, which is beneficial to the photocatalytic hydrogen evolution.

Scanning electron microscopy (SEM) images demonstrate that the three as-synthesized polymers present different aggregated morphologies (Fig. 2d-f and Fig. S2). PyTP-1 shows a nanorod morphology with smooth surface, PyTP-2 exhibits a nanoparticle morphology with porous texture structure, while PyTP3 has a dense packed layer morphology. The water wettability of the resulting polymer photocatalysts was estimated by the water contact angle. The result reveals that the contact angle decreases from $96.6^{\circ}$ for PyTP-1 to $86.5^{\circ}$ for PyTP-2 and to $79.0^{\circ}$ for PyTP-3 with increasing number of thiophene rings (Fig. $2 \mathrm{~g}-\mathrm{i}$ ).

The photophysical properties for the three polymers were studied by the UV-Vis diffuse reflectance and photo-luminescence (PL) emission spectroscopy. The UV-Vis reflectance spectra manifest that the three polymers show a strong light absorption ability in the whole visible light range (Fig. 3a), and a clear red-shift from PyTP-1 to PyTP-2 and to PyTP-3 with increasing number of thiophene rings is observed, indicating the extended conjugation degree of the polymer skeletons. Although the building block of dithieno[3,2-b:2',3'-d] thiophene shows an extended coplanar structure than thieno[3,2- $b]$ thiophene, PyTP3 shows a slightly broader UV-Vis reflectance spectrum than PyTP-2, which could be ascribed to the relatively lower polymerization degree of PyTP-3 than that of PyTP-2, as evidenced by the higher content of the unreacted $\mathrm{Br}$ end group in PyTP-3 (Fig. 2b, c). Correspondingly, the optical band gaps based on the absorption edge of the UV-Vis reflectance spectra were calculated to be 2.02, 1.93 and $1.88 \mathrm{eV}$ for PyTP-1, PyTP-2 and PyTP-
3, respectively (Fig. S3). As shown in Fig. 3b, the PL emission spectra also reveal that the PL emission peaks for PyTP-2 and PyTP-3 show an obvious red-shift with lower fluorescent emission intensity compared with PyTP-1. The low PL emission implies a low recombination possibility of photo-induced electrons and holes through fluorescence radiation. Therefore, the photo-induced electrons in PyTP-2 and PyTP-3 might have more chance to reduce protons to generate $\mathrm{H}_{2}$ than those in PyTP-1. The cyclic voltammetry (CV) measurement reveals that the three polymers present different highest occupied molecular orbital (HOMO) energy levels (Fig. S4), but there is no significant difference in the lowest unoccupied molecular orbital (LUMO) energy levels for the three polymers (Fig. 3c), possibly due to the similar chemical structure of the polymers. The result of photocurrent measurement shows that PyTP-2 has a stronger current response under UV-Vis light irradiation than PyTP-1 and PyTP-3 (Fig. 3d), implying that PyTP-2 could produce more photo-induced charge carriers during photocatalytic reaction, which is beneficial to the photocatalytic hydrogen evolution.

The photocatalytic hydrogen evolution experiment of the assynthesized polymer photocatalysts $(10 \mathrm{mg})$ was carried out by using AA as a sacrificial hole-scavenger and DMF as a watersoluble co-solvent. AA was employed as the sacrificial agent since the polymers show a much higher photocatalytic activity in AA solution than that in triethylamine (TEA) or triethanolamine (TEOA) solution (Fig. S5). All the three polymers present a high photocatalytic activity for hydrogen evolution under UV-Vis light irradiation (Fig. 4a), while PyTP-2 shows a much higher photocatalytic activity than PyTP-1 and PyTP-3. A remarkable HER of $44.64 \mathrm{mmol} \mathrm{h}^{-1} \mathrm{~g}^{-1}$ could be achieved by PyTP-2 under the simulated sunlight irradiation without using $\mathrm{Pt}$ co-catalyst (Table 1). The control photocatalytic experiments demonstrate that no any hydrogen could be detected in pure water or in the absence of polymer photocatalyst, indicating that both the polymer photocatalyst and sacrificial agent play crucial roles in the photocatalytic hydrogen evolution. Compared with PyTP-1, PyTP-2 and PyTP-3 show much higher HER because of their broader light absorption range and higher hydrophilicity that increases the contact between water molecules and the polymer photocatalyst. Taking into account that PyTP-3 shows a slightly 

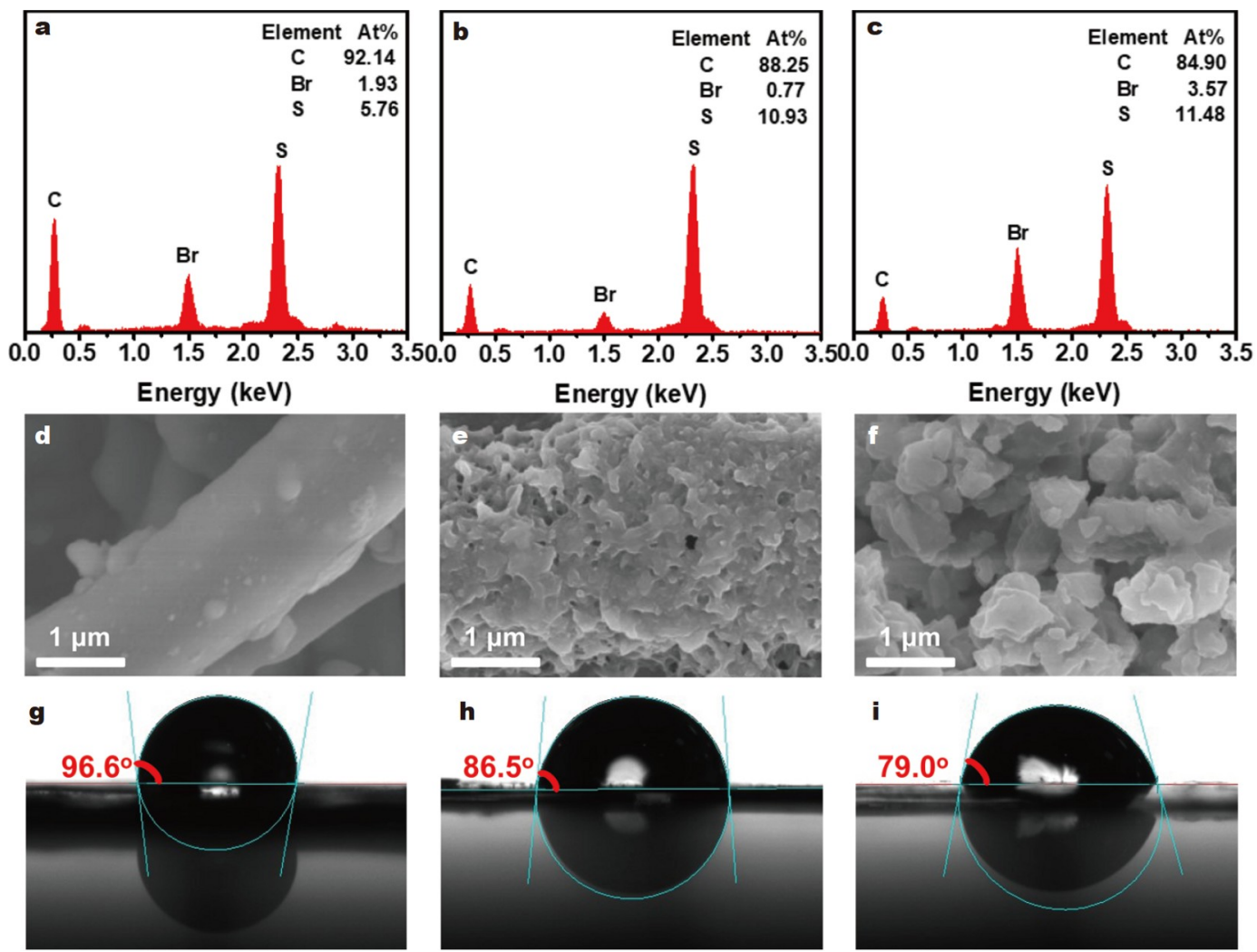

Figure 2 The EDX spectra of PyTP-1 (a), PyTP-2 (b) and PyTP-3 (c); the SEM images of PyTP-1 (d), PyTP-2 (e) and PyTP-3 (f); optical photos of $\mathrm{H}_{2} \mathrm{O}$ on the surfaces of PyTP-1 (g), PyTP-2 (h) and PyTP-3 (i) and their contact angles.
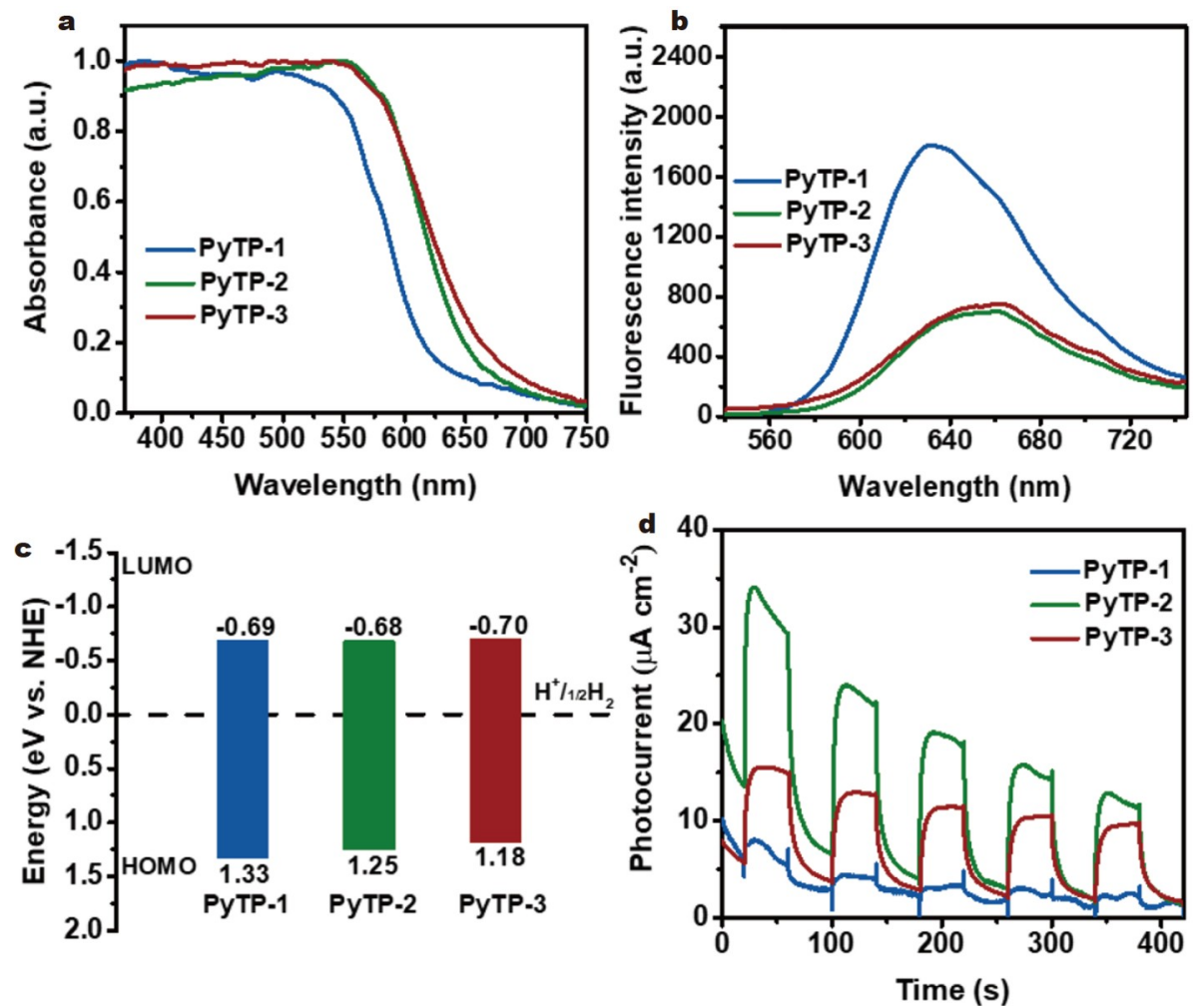

Figure 3 (a) UV/Vis reflectance spectra of the polymers; (b) PL spectra of the polymers (inset: photographs of the polymers under UV light); (c) energy band positions; (d) photocurrent curves of the polymers. 

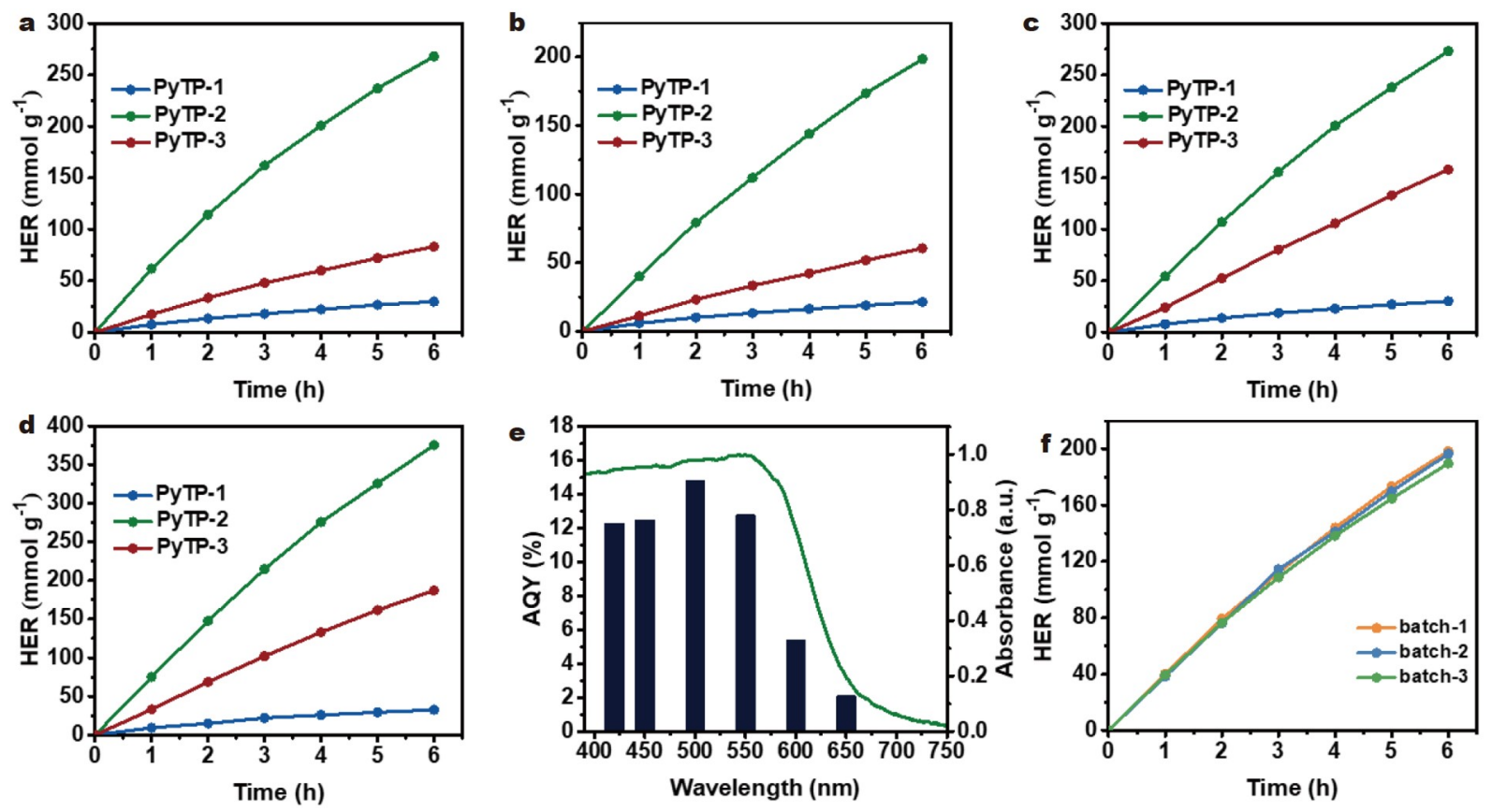

Figure 4 (a) Hydrogen generation function $v s$. time of the bare polymers $(10 \mathrm{mg})$ under UV/Vis light $(\lambda>300 \mathrm{~nm})$, and (b) visible light $(\lambda>420 \mathrm{~nm})$; (c) hydrogen generation function $v s$. time of the polymers $(10 \mathrm{mg})$ with Pt co-catalyst under visible light $(\lambda>420 \mathrm{~nm})$, and $(\mathrm{d}) \mathrm{UV} / \mathrm{Vis}$ light $(\lambda>300 \mathrm{~nm})$; (e) the AQY plots and UV/Vis reflectance spectrum of PyTP-2; (f) hydrogen generation function vs. time of PyTP-2 from different batches (10 mg) under visible light $(\lambda>420 \mathrm{~nm})$.

Table 1 Photophysical properties and HER for the polymers

\begin{tabular}{|c|c|c|c|c|c|c|}
\hline Polymer & $\begin{array}{l}\text { LUMO }^{\mathrm{a}} \\
\quad(\mathrm{eV})\end{array}$ & $\begin{array}{c}E_{\mathrm{g}}^{\mathrm{b}} \\
(\mathrm{eV})\end{array}$ & $\begin{array}{c}\text { HER }^{\mathrm{c}} \\
\left(\mathrm{mmol} \mathrm{h}^{-1} \mathrm{~g}^{-1}\right)\end{array}$ & $\begin{array}{c}\text { HER }^{\mathrm{d}} \\
\left(\mathrm{mmol} \mathrm{h}^{-1} \mathrm{~g}^{-1}\right)\end{array}$ & $\begin{array}{c}\mathrm{HER}^{\mathrm{e}} \\
\left(\mathrm{mmol} \mathrm{h}^{-1} \mathrm{~g}^{-1}\right)\end{array}$ & $\begin{array}{c}\operatorname{HER}^{\mathrm{f}} \\
\left(\mathrm{mmolh}^{-1} \mathrm{~g}^{-1}\right)\end{array}$ \\
\hline PyTP-1 & -0.69 & 2.02 & 3.56 & 5.05 & 4.97 & 5.54 \\
\hline РyTP-2 & -0.68 & 1.93 & 33.07 & 45.51 & 44.64 & 62.52 \\
\hline PyTP-3 & -0.70 & 1.88 & 10.08 & 26.35 & 13.86 & 31.19 \\
\hline
\end{tabular}

a) LUMO energy level obtained by CV results and UV/Vis spectra. b) Calculated from the absorption edge. c) Polymers were irradiated by visible light $(\lambda>$ $420 \mathrm{~nm})$. d) Polymers with Pt were irradiated by visible light. e) Polymers were irradiated by UV/Vis light $(\lambda>300 \mathrm{~nm})$. f) Polymers with Pt were irradiated by $\mathrm{UV} / \mathrm{V}$ is light $(\lambda>300 \mathrm{~nm})$.

broader light absorption range and higher hydrophilicity than PyTP-2, the higher HER achieved by PyTP-2 could be ascribed to its higher surface area offering plentiful available active sites for hydrogen evolution. In addition, all the polymers also show high photocatalytic activity under visible light irradiation $(\lambda>420 \mathrm{~nm})$ (Fig. $4 \mathrm{~b}$ ). In particular, the bare PyTP-2 could give a high HER of $33.07 \mathrm{mmol} \mathrm{h}^{-1} \mathrm{~g}^{-1}$ under visible light. The high visible light activity of the polymers could be ascribed to the broad light absorption in the visible light range, as evidenced by the UV-Vis reflectance spectra. The high HER of $33.07 \mathrm{mmol} \mathrm{h}^{-1} \mathrm{~g}^{-1}$ for the bare PyTP-2 under visible light outperforms that of most previously reported organic photocatalysts (Table S1). For example, the triazine-based polymer of triazine-Th-CPP exhibited an HER of $4.43 \mathrm{mmol} \mathrm{h}^{-1} \mathrm{~g}^{-1}$ under visible-light irradiation [43], the D-A conjugated polymer of BTT-CPP showed an HER of $12.63 \mathrm{mmol} \mathrm{h}^{-1} \mathrm{~g}^{-1}$ under visible light [40], the sulfone-based conjugated copolymer of PS-5 gave an HER of $7.5 \mathrm{mmol} \mathrm{h}^{-1} \mathrm{~g}^{-1}$ under visible light illumination [48], and the linear conjugated polymer P2 showed an HER of $10.85 \mathrm{mmol} \mathrm{h}^{-1} \mathrm{~g}^{-1}$ [20]. Moreover, a direct comparison of PyTP2 with the counterpart of $\mathrm{CP} 1$ produced from pyrene and bithiophene demonstrates that PyTP-2 shows a much higher HER (33.07 $\left.\mathrm{mmol} \mathrm{h}^{-1} \mathrm{~g}^{-1}\right)$ than CP1 (15.97 $\left.\mathrm{mmol} \mathrm{h}^{-1} \mathrm{~g}^{-1}\right)$ under visible light illumination [7]. The improvement in the photocatalytic performance of PyTP-2 could be ascribed to the planar molecular structure of the acceptor unit of thieno[3,2-b]thiophene (which promotes the charge transmission along the polymer skeleton), compared with the twisted molecular structure of bithiophene.

The influence of the photocatalyst dosage on the HER was also assessed by altering the mass loading of PyTP-2 from 5 to $50 \mathrm{mg}$. The absolute amount of the produced $\mathrm{H}_{2}$ increases with increasing amount of the PyTP-2 photocatalyst (Fig. S6a). However, the mass-normalized HER decreases with increasing amount of PyTP-2 (Fig. S6b), since the excess mass loading of PyTP-2 in the reaction system with a fixed volume could result in the aggregation of polymer particles and decrease the dispersity of PyTP-2 in the photocatalytic reaction system, leading to poor light absorption and transmission, and a low utilization efficiency of active sites in PyTP-2.

To reveal the influence of residual $\mathrm{Pd}$ on the photocatalytic activity for the three polymers, ICP-OES measurement was 
conducted to detect the $\mathrm{Pd}$ residue from the $\mathrm{Pd}_{2}(\mathrm{dba})_{3}$ catalyst (Fig. S7). The result reveals that the Pd contents are $0.24,0.14$ and $0.19 \mathrm{wt} \%$ for PyTP-1, PyTP-2 and PyTP-3, respectively. PyTP-2 shows a lower Pd content but a higher photocatalytic activity than PyTP-1 and PyTP-3, indicating that the large difference in photocatalytic performance of the polymers should be mainly attributed to the molecular structure variation of the three polymers. We need to point out that it is very difficult to synthesize the palladium-free polymer photocatalysts using Pdcatalyzed polymerization since the total removal of the $\mathrm{Pd}$ residue is nearly impossible, as mentioned by Cooper and coworkers [49]. However, the photocatalytic activity of the polymer photocatalysts could be further enhanced by using $\mathrm{Pt}$ as a co-catalyst. The study on the influence of the Pt content on the photocatalytic activity reveals that $0.2 \mathrm{wt} \% \mathrm{Pt}$ is an optimal content for achieving a high photocatalytic performance (Fig. S8). The HER of PyTP-2 with loading $0.2 \mathrm{wt} \% \mathrm{Pt}$ could be improved to $45.51 \mathrm{mmol} \mathrm{h}^{-1} \mathrm{~g}^{-1}$ under visible light irradiation $(\lambda$ $>420 \mathrm{~nm}$ ) (Fig. 4c), and further improved to $62.52 \mathrm{mmol} \mathrm{h}^{-1} \mathrm{~g}^{-1}$ under full-arc spectrum $(\lambda>300 \mathrm{~nm})$ (Fig. $4 \mathrm{~d})$. The improvement in the photocatalytic performance for the Pt-loaded polymer photocatalyst could be explained by the enhanced electron transfer from the polymer to Pt surface, which improves the separation efficiency of charge carriers.

The measurement of apparent quantum yields (AQYs) of the most photo-active polymer of PyTP-2 demonstrates that more than $12 \%$ AQY could be obtained at the incident light wavelengths of 420,450, 500 and $550 \mathrm{~nm}$ since the polymer shows a strong light absorption capability in this spectral region, and a maximal AQY of $14.8 \%$ is achieved at $500 \mathrm{~nm}$ (Fig. 4e). How- ever, the AQY diminishes to $5.4 \%$ at $600 \mathrm{~nm}$, and further to $2.1 \%$ at $650 \mathrm{~nm}$ as the incident light wavelength increases, because PyTP-2 shows a low light absorption ability in this spectral range. This result implies that broadening the light absorption ability of polymer photocatalysts is an efficient strategy to promote the photocatalytic performance, particularly for the visible light photocatalytic reactivity for hydrogen evolution. To demonstrate the reproducibility for the PyTP-2 photocatalyst, another two batches of PyTP-2 were also prepared under the identical polymerization conditions. The batch-to-batch polymers exhibit very similar photocatalytic activity for hydrogen evolution (Fig. 4f), indicating the outstanding repeatability for both the synthesis of polymer and its photocatalytic performance.

The cycling photocatalytic measurement demonstrates that PyTP-2 can still maintain an HER of $17.5 \mathrm{mmol} \mathrm{h}^{-1} \mathrm{~g}^{-1}$ after $24 \mathrm{~h}$ (Fig. S9). Although the photocatalytic stability of PyTP-2 is less than that of the state-of-art polymer photocatalysts [50-52], the HER of $17.5 \mathrm{mmol} \mathrm{h}^{-1} \mathrm{~g}^{-1}$ of PyTP-2 after $24 \mathrm{~h}$ photocatalytic reaction is still much higher than that of most reported polymer photocatalysts [53-55]. The structure characterizations of the recovered sample of PyTP-2 after $24 \mathrm{~h}$ photocatalytic reaction demonstrate that no any obvious change in the chemical structure could be observed, as evidenced by the results of FT-IR and solid state ${ }^{13} \mathrm{C}$ NMR (Fig. 5a, b). However, the UV-Vis reflectance spectrum and the $\mathrm{PL}$ emission spectrum for the recovered sample show obvious blue shift (Fig. 5c, d), implies the decrease of conjugation degree of the polymer skeleton, which might be attributed to the breakage of the polymer backbone resulting from the photodegradation during the long-
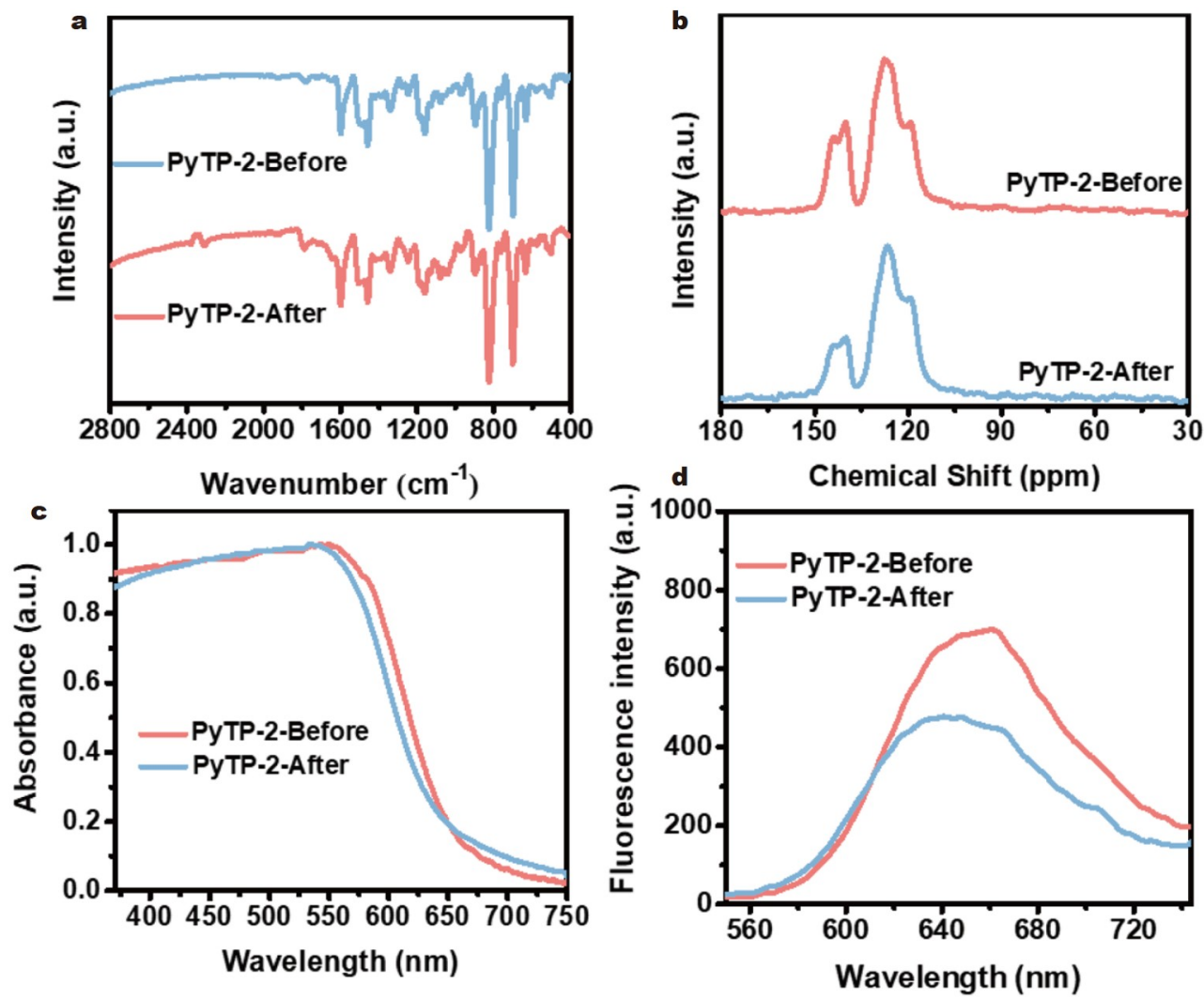

Figure 5 (a) FT-IR spectra, (b) solid-state ${ }^{13} \mathrm{C}$ CP-MAS NMR spectra, (c) UV-Vis reflectance spectra and (d) photo-luminescent spectra of the polymer PyTP-2 before and after photocatalytic reaction under visible light $(\lambda>420 \mathrm{~nm})$ for $24 \mathrm{~h}$ in a mixture of AA/DMF/water. 
term photocatalytic reaction [41], thus leading to obvious fading in the HER.

Recent studies demonstrated that organic polymers could be also used as photocatalysts for oxygen evolution in water splitting [56,57]. Therefore, the photocatalytic oxygen evolution reaction was also conducted by utilizing the most photoactive polymer PyTP-2. No any oxygen could be detected when the assynthesized PyTP-2 was irradiated by broadband light for $6 \mathrm{~h}$ in pure water in the absence of electron scavenger or oxidation cocatalyst. However, the photocatalytic activity for oxygen evolution could be significantly improved by adding $\mathrm{AgNO}_{3}$ as the electron scavenger, $\mathrm{Co}\left(\mathrm{NO}_{3}\right)_{2}$ as the co-catalyst, and the $\mathrm{pH}$ buffer agent of $\mathrm{La}_{2} \mathrm{O}_{3}$. PyTP-2 shows a high photocatalytic activity in the early first one hour with an oxygen evolution rate (OER) of $275 \mu \mathrm{mol} \mathrm{h}^{-1} \mathrm{~g}^{-1}$. Afterwards, the photocatalytic activity decreases, and an average OER of $58.37 \mu \mathrm{molh}^{-1} \mathrm{~g}^{-1}$ was obtained during the photocatalytic oxygen evolution experiment for $4 \mathrm{~h}$ (Fig. S10). Since the PyTP-2 can well maintain its chemical structure during the photocatalytic $\mathrm{O}_{2}$ evolution reaction (Fig. S11a-c), the fast fading of OER for PyTP-2 could be attributed to the deposition of metallic Ag on the surface of the polymer photocatalyst (Fig. S11d), which leads to a light shading effect and hinders light absorption by the polymer photocatalyst $[56,57]$. These results demonstrate that there is a wealth of opportunity to produce organic polymer photocatalysts that photo-drive water splitting to produce hydrogen and oxygen.

\section{CONCLUSIONS}

In conclusion, a series of conjugated polymer photocatalysts consisting of various fused-thiophene rings and pyrene unit were synthesized by direct $\mathrm{C}-\mathrm{H}$ arylation coupling reaction. Due to the introduction of different thiophene units and the D-A polymer structure, all of the photocatalysts show a narrow band gap with high photocatalytic activity for hydrogen evolution. A remarkable HER of $33.07 \mathrm{mmol} \mathrm{h}^{-1} \mathrm{~g}^{-1}$ under visible light was achieved by PyTP-2 without using Pt co-catalyst. The high photocatalytic activity of the polymer could be ascribed to its higher surface area offering plentiful available active sites, the broad light absorption in the visible light range, and the promoted charge transmission ability due to the improved coplanarity of the polymer chain. In addition, PyTP-2 shows photocatalytic activity for oxygen evolution, which paves the way to develop excellent bifunctional organic photocatalysts for water splitting. This work not only demonstrates that direct $\mathrm{C}-\mathrm{H}$ arylation coupling polymerization is a simple and promising synthetic strategy for the preparation of organic photocatalysts, but also reveals that the molecular structure design is crucial to enhance the photocatalytic performance of polymeric photocatalysts under visible light.

\section{Received 8 May 2021; accepted 9 July 2021;}

published online 2 September 2021

1 Wang Z, Li C, Domen K. Recent developments in heterogeneous photocatalysts for solar-driven overall water splitting. Chem Soc Rev, 2019, 48: 2109-2125

2 Wang Y, Vogel A, Sachs M, et al. Current understanding and challenges of solar-driven hydrogen generation using polymeric photocatalysts. Nat Energy, 2019, 4: 746-760

3 Maeda K, Domen K. Photocatalytic water splitting: Recent progress and future challenges. J Phys Chem Lett, 2010, 1: 2655-2661

4 Zhao C, Chen Z, Shi R, et al. Recent advances in conjugated polymers for visible-light-driven water splitting. Adv Mater, 2020, 32: 1907296

5 Jayakumar J, Chou HH. Recent advances in visible-light-driven hydrogen evolution from water using polymer photocatalysts. ChemCatChem, 2020, 12: 689-704

6 Dai C, Liu B. Conjugated polymers for visible-light-driven photocatalysis. Energy Environ Sci, 2020, 13: 24-52

7 Huang WY, Shen ZQ, Cheng JZ, et al. C-H activation derived CPPs for photocatalytic hydrogen production excellently accelerated by a DMF cosolvent. J Mater Chem A, 2019, 7: 24222-24230

8 Han $\mathrm{C}$, Dong $\mathrm{P}$, Tang $\mathrm{H}$, et al. Realizing high hydrogen evolution activity under visible light using narrow band gap organic photocatalysts. Chem Sci, 2021, 12: 1796-1802

9 Jiang JX, Su F, Trewin A, et al. Synthetic control of the pore dimension and surface area in conjugated microporous polymer and copolymer networks. J Am Chem Soc, 2008, 130: 7710-7720

10 Sprick RS, Jiang JX, Bonillo B, et al. Tunable organic photocatalysts for visible-light-driven hydrogen evolution. J Am Chem Soc, 2015, 137: 3265-3270

11 Yang C, Ma BC, Zhang L, et al. Molecular engineering of conjugated polybenzothiadiazoles for enhanced hydrogen production by photosynthesis. Angew Chem Int Ed, 2016, 55: 9202-9206

$12 \mathrm{Xu} \mathrm{Y}$, Mao N, Zhang C, et al. Rational design of donor- $\pi$-acceptor conjugated microporous polymers for photocatalytic hydrogen production. Appl Catal B-Environ, 2018, 228: 1-9

13 Sprick RS, Wilbraham L, Bai Y, et al. Nitrogen containing linear poly (phenylene) derivatives for photo-catalytic hydrogen evolution from water. Chem Mater, 2018, 30: 5733-5742

14 Jiang JX, Su F, Trewin A, et al. Conjugated microporous poly(aryleneethynylene) networks. Angew Chem Int Ed, 2007, 46: 8574-8578

15 Wang X, Maeda K, Thomas A, et al. A metal-free polymeric photocatalyst for hydrogen production from water under visible light. Nat Mater, 2009, 8: 76-80

16 Liu J, Liu Y, Liu N, et al. Metal-free efficient photocatalyst for stable visible water splitting via a two-electron pathway. Science, 2015, 347: 970-974

17 Yang D, Li LL, Xiao G, et al. Steering charge kinetics in metal-free g$\mathrm{C}_{3} \mathrm{~N}_{4} /$ melem hybrid photocatalysts for highly efficient visible-lightdriven hydrogen evolution. Appl Surf Sci, 2020, 510: 145345

18 Bai Y, Wilbraham L, Slater BJ, et al. Accelerated discovery of organic polymer photocatalysts for hydrogen evolution from water through the integration of experiment and theory. J Am Chem Soc, 2019, 141: 9063-9071

19 Shu G, Li Y, Wang Z, et al. Poly(dibenzothiophene-S,S-dioxide) with visible light-induced hydrogen evolution rate up to $44.2 \mathrm{mmol} \mathrm{h}^{-1} \mathrm{~g}^{-1}$ promoted by $\mathrm{K}_{2} \mathrm{HPO}_{4}$. Appl Catal B-Environ, 2020, 261: 118230

20 Wang WR, Li J, Li Q, et al. Side-chain-extended conjugation: A strategy for improving the photocatalytic hydrogen production performance of a linear conjugated polymer. J Mater Chem A, 2021, 9: 8782-8791

21 Sprick RS, Bonillo B, Clowes R, et al. Visible-light-driven hydrogen evolution using planarized conjugated polymer photocatalysts. Angew Chem Int Ed, 2016, 55: 1792-1796

22 Zhang XH, Wang XP, Xiao J, et al. Synthesis of 1,4-diethynylbenzenebased conjugated polymer photocatalysts and their enhanced visible/ near-infrared-light-driven hydrogen production activity. J Catal, 2017, 350: 64-71

23 Mothika VS, Sutar P, Verma P, et al. Regulating charge-transfer in conjugated microporous polymers for photocatalytic hydrogen evolution. Chem Eur J, 2019, 25: 3867-3874

24 Shu C, Zhao Y, Zhang C, et al. Bisulfone-functionalized organic polymer photocatalysts for high-performance hydrogen evolution. ChemSusChem, 2020, 13: 369-375

25 Sprick RS, Bai Y, Guilbert AAY, et al. Photocatalytic hydrogen evolution from water using fluorene and dibenzothiophene sulfone-conjugated microporous and linear polymers. Chem Mater, 2019, 31: 305313

26 Wang Z, Yang X, Yang $\mathrm{T}$, et al. Dibenzothiophene dioxide based conjugated microporous polymers for visible-light-driven hydrogen production. ACS Catal, 2018, 8: 8590-8596 
27 Zhao Y, Ma W, Xu Y, et al. Effect of linking pattern of dibenzothiophene-S,S-dioxide-containing conjugated microporous polymers on the photocatalytic performance. Macromolecules, 2018, 51: 9502-9508

28 Wang X, Chen L, Chong SY, et al. Sulfone-containing covalent organic frameworks for photocatalytic hydrogen evolution from water. Nat Chem, 2018, 10: 1180-1189

29 Jin E, Lan Z, Jiang Q, et al. 2D sp ${ }^{2}$ carbon-conjugated covalent organic frameworks for photocatalytic hydrogen production from water. Chem, 2019, 5: 1632-1647

30 Gottschling K, Savasci G, Vignolo-González H, et al. Rational design of covalent cobaloxime-covalent organic framework hybrids for enhanced photocatalytic hydrogen evolution. J Am Chem Soc, 2020, 142: 1214612156

31 Li W, Huang X, Zeng T, et al. Thiazolo[5,4- $d$ ]thiazole-based donoracceptor covalent organic framework for sunlight-driven hydrogen evolution. Angew Chem Int Ed, 2021, 60: 1869-1874

32 Kong D, Han X, Xie J, et al. Tunable covalent triazine-based frameworks (CTF-0) for visible-light-driven hydrogen and oxygen generation from water splitting. ACS Catal, 2019, 9: 7697-7707

33 Meier CB, Clowes R, Berardo E, et al. Structurally diverse covalent triazine-based framework materials for photocatalytic hydrogen evolution from water. Chem Mater, 2019, 31: 8830-8838

34 Huang $\mathrm{W}, \mathrm{He} \mathrm{Q}, \mathrm{Hu} \mathrm{Y}$, et al. Molecular heterostructures of covalent triazine frameworks for enhanced photocatalytic hydrogen production. Angew Chem Int Ed, 2019, 58: 8676-8680

35 Liu M, Huang Q, Wang S, et al. Crystalline covalent triazine frameworks by in situ oxidation of alcohols to aldehyde monomers. Angew Chem Int Ed, 2018, 57: 11968-11972

$36 \mathrm{Xu} \mathrm{Y,} \mathrm{Mao} \mathrm{N,} \mathrm{Feng} \mathrm{S,} \mathrm{et} \mathrm{al.} \mathrm{Perylene-containing} \mathrm{conjugated} \mathrm{micro-}$ porous polymers for photocatalytic hydrogen evolution. Macromol Chem Phys, 2017, 218: 1700049

37 Xiang Y, Wang X, Rao L, et al. Conjugated polymers with sequential fluorination for enhanced photocatalytic $\mathrm{H}_{2}$ evolution via protoncoupled electron transfer. ACS Energy Lett, 2018, 3: 2544-2549

38 Cheng JZ, Liu LL, Liao G, et al. Achieving an unprecedented hydrogen evolution rate by solvent-exfoliated CPP-based photocatalysts. J Mater Chem A, 2020, 8: 5890-5899

39 Gao X, Shu C, Zhang C, et al. Substituent effect of conjugated microporous polymers on the photocatalytic hydrogen evolution activity. J Mater Chem A, 2020, 8: 2404-2411

40 Wang J, Ouyang G, Wang D, et al. Enhanced photocatalytic performance of donor-acceptor-type polymers based on a thiophene-contained polycyclic aromatic unit. Macromolecules, 2021, 54: 2661-2666

41 Cheng C, Wang X, Wang F. Pyrene-alt-dibenzothiophene-S,S-dioxide copolymers for highly efficient photocatalytic hydrogen production: The role of linking pattern. Appl Surf Sci, 2019, 495: 143537

42 Cheng C, Wang X, Lin Y, et al. The effect of molecular structure and fluorination on the properties of pyrene-benzothiadiazole-based conjugated polymers for visible-light-driven hydrogen evolution. Polym Chem, 2018, 9: 4468-4475

43 Wang J, Ouyang G, Wang Y, et al. 1,3,5-Triazine and dibenzo $[b, d]$ thiophene sulfone based conjugated porous polymers for highly efficient photocatalytic hydrogen evolution. Chem Commun, 2020, 56: 1601-1604

44 Zong X, Miao X, Hua S, et al. Structure defects assisted photocatalytic $\mathrm{H}_{2}$ production for polythiophene nanofibers. Appl Catal B-Environ, 2017, 211: 98-105

45 Sprick RS, Aitchison CM, Berardo E, et al. Maximising the hydrogen evolution activity in organic photocatalysts by co-polymerisation. J Mater Chem A, 2018, 6: 11994-12003

46 Bernhardt S, Kastler M, Enkelmann V, et al. Pyrene as chromophore and electrophore: Encapsulation in a rigid polyphenylene shell. Chem Eur J, 2006, 12: 6117-6128

47 Wang X, Wang M. Synthesis of donor-acceptor conjugated polymers based on benzo[1,2-b:4,5- $\left.b^{\prime}\right]$ dithiophene and 2,1,3-benzothiadiazole via direct arylation polycondensation: towards efficient $\mathrm{C}-\mathrm{H}$ activation in nonpolar solvents. Polym Chem, 2014, 5: 5784-5792

48 Ye H, Wang Z, Yang Z, et al. Bandgap engineering of novel peryleno $[1,12-b c d]$ thiophene sulfone-based conjugated co-polymers for significantly enhanced hydrogen evolution without co-catalyst. J Mater Chem A, 2020, 8: 20062-20071

49 Sachs M, Cha H, Kosco J, et al. Tracking charge transfer to residual metal clusters in conjugated polymers for photocatalytic hydrogen evolution. J Am Chem Soc, 2020, 142: 14574-14587

50 Shu C, Han C, Yang X, et al. Boosting the photocatalytic hydrogen evolution activity for $\mathrm{D}-\pi-\mathrm{A}$ conjugated microporous polymers by statistical copolymerization. Adv Mater, 2021, 33: 2008498

51 Guo L, Niu Y, Razzaque S, et al. Design of $\mathrm{D}-\mathrm{A}_{1}-\mathrm{A}_{2}$ covalent triazine frameworks via copolymerization for photocatalytic hydrogen evolution. ACS Catal, 2019, 9: 9438-9445

52 Liu C, Xiao Y, Yang Q, et al. A highly fluorine-functionalized 2D covalent organic framework for promoting photocatalytic hydrogen evolution. Appl Surf Sci, 2021, 537: 148082

53 Zhao Z, Zheng Y, Wang C, et al. Fabrication of robust covalent organic frameworks for enhanced visible-light-driven $\mathrm{H}_{2}$ evolution. ACS Catal, 2021, 11: 2098-2107

54 Wang GB, Zhu FC, Lin QQ, et al. Rational design of benzodifuranfunctionalized donor-acceptor covalent organic frameworks for photocatalytic hydrogen evolution from water. Chem Commun, 2021, 57: $4464-4467$

55 Yu F, Wang Z, Zhang S, et al. Construction of polymeric carbon nitride and dibenzothiophene dioxide-based intramolecular donor-acceptor conjugated copolymers for photocatalytic $\mathrm{H}_{2}$ evolution. Nanoscale Adv, 2021, 3: 1699-1707

56 Lan ZA, Fang Y, Zhang Y, et al. Photocatalytic oxygen evolution from functional triazine-based polymers with tunable band structures. Angew Chem Int Ed, 2018, 57: 470-474

57 Sprick RS, Chen Z, Cowan AJ, et al. Water oxidation with cobalt-loaded linear conjugated polymer photocatalysts. Angew Chem Int Ed, 2020, 59: $18695-18700$

Acknowledgements This work was financially supported by the National Natural Science Foundation of China (21574077 and 21304055), and the Fundamental Research Funds for the Central Universities (GK202102005).

Author contributions Xiang S synthesized the materials and performed the photocatalytic hydrogen generation experiments; Han C conducted photocatalytic oxygen generation experiment; Shu $\mathrm{C}$ contributed to the data analyses and discussion; Xiang $\mathrm{S}$ wrote the paper with the support from Jiang JX and Zhang C. All authors contributed to the general discussion.

Conflict of interest The authors declare no conflict of interest.

Supplementary information Experimental details and supporting data are available in the online version of the paper.

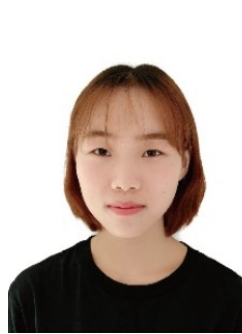

Sihui Xiang is a master's student at the School of Materials Science and Engineering, Shaanxi Normal University. Her research focuses on conjugated organic polymers and photocatalytic hydrogen evolution. 


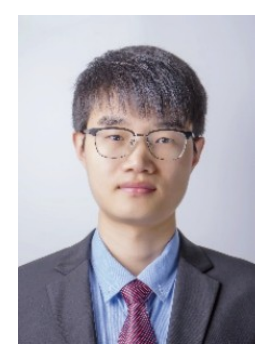

Chong Zhang is an assistant professor at the School of Materials Science and Engineering, Shaanxi Normal University. He received his PhD degree in 2019 from Shaanxi Normal University. His main research topics are devoted to porous organic polymer electrodes for rechargeable batteries, aqueous electrolytes, and photocatalytic hydrogen evolution.

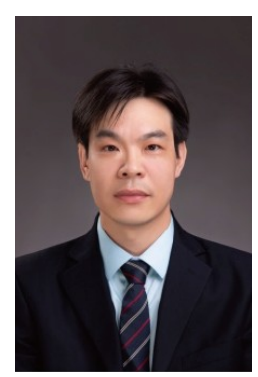

Jia-Xing Jiang is a professor at the School of Materials Science and Engineering, Shaanxi Normal University. He received his $\mathrm{PhD}$ degree in 2006 from the South China University of Technology, and afterward conducted his postdoc research at the University of Liverpool (2006.08-2011.12). His current research interests mainly focus on conjugated microporous polymers for photocatalytic hydrogen evolution and energy storage.

\section{高效光催化制氢噻吩基共轭聚合物光催化剂的结构} 调控

向思慧, 韩昌志, 舒畅, 张崇*, 蒋加兴*

摘要 近年来, 共轭聚合物光催化剂因其可调的分子结构和电子性能 在光催化分解水制氢领域引起广泛关注. 本文报道了三种以芘单元为 电子供体, 不同的噻吩单元为电子受体的含噻吩基窄带隙共轭聚合物, 聚合物均通过直接 $\mathrm{C}-\mathrm{H}$ 芳基化偶联反应一步聚合. 研究发现, 通过调整 稠合噻吩环的数目可以调节聚合物的带隙, 可见光吸收范围随稠合噻 吩环数量增加而扩大; 供受体单元的平面分子结构有利于电荷沿聚合 物骨架的传递; D-A型聚合物结构可促进光生电子和空穴的分离. 最终, 在模拟可见光 $(\lambda>420 \mathrm{~nm})$ 照射且未加入 Pt助催化剂的条件下, 具有优 异结构的PyTP-2光催化产氢速率(HER)达 $33.07 \mathrm{mmol} \mathrm{h}^{-1} \mathrm{~g}^{-1}$. 此外, PyTP-2 还具有良好的光催化产氧活性, 其平均产氧速率 (OER) 为 $58.37 \mu \mathrm{mol} \mathrm{h}^{-1} \mathrm{~g}^{-1}$. 